إضافة بذور زهرة الثمس وبيكاربونات الصوديوم إلى العلائق وأثرها في إنتاج الحليب ومكوناته وبعض قياسات الام في النعاج المبات

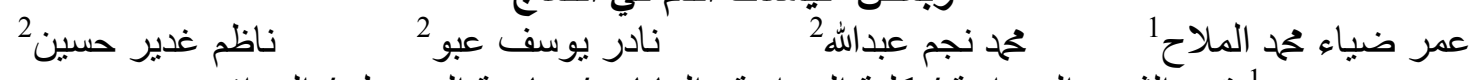

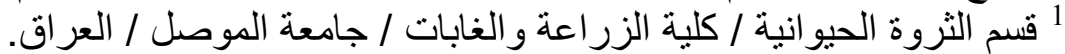

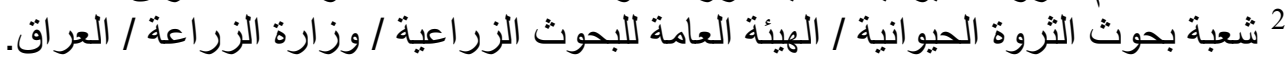

E-mail: omaralmallah@yahoo.com

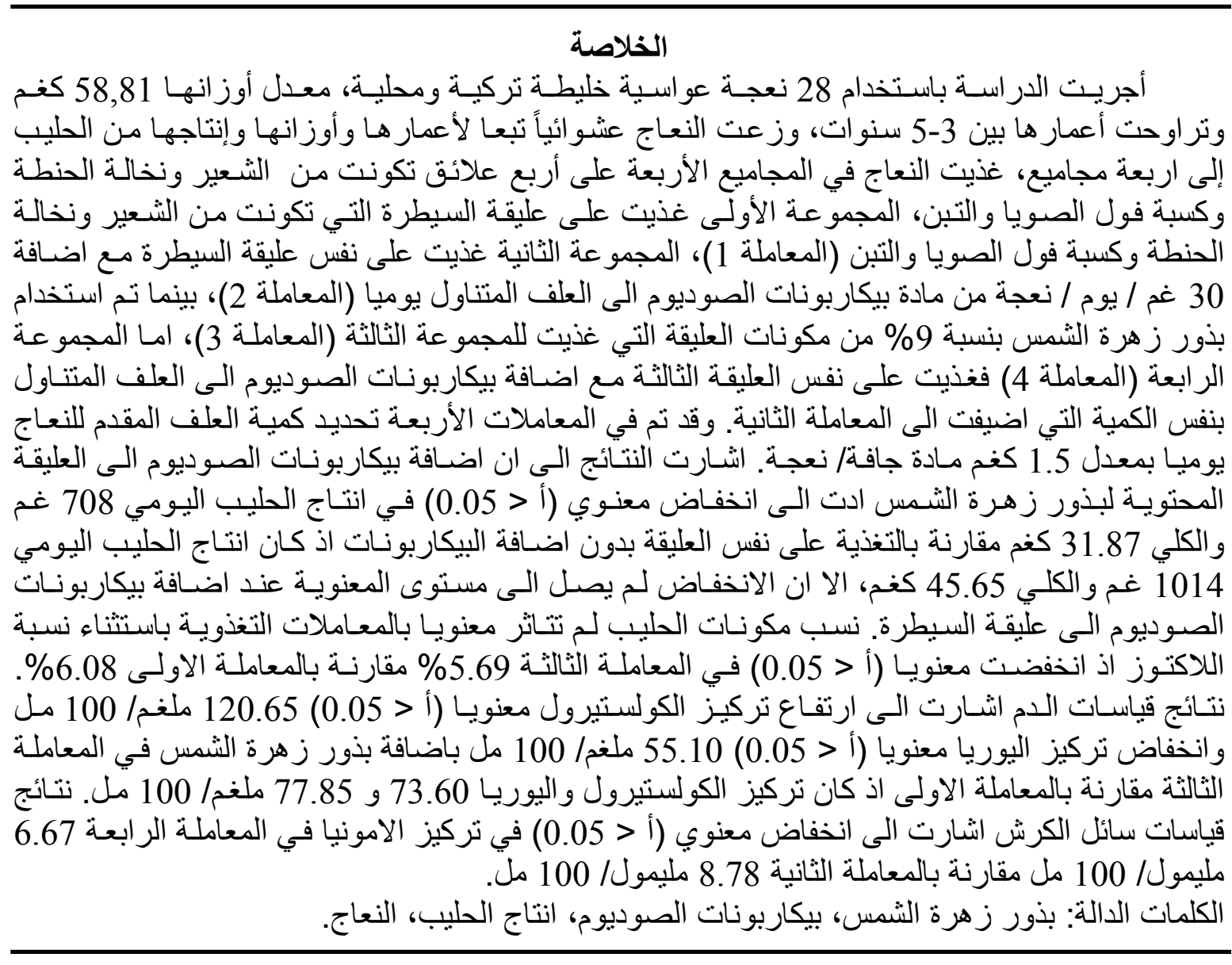

تاريخ نسلم البحث: 2012/1/17 وقبوله: 2012/5/21.

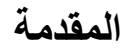

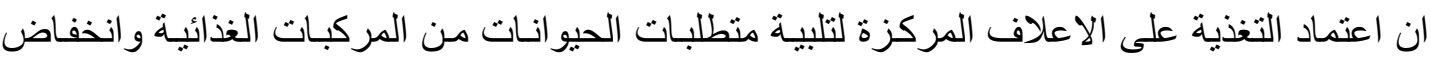

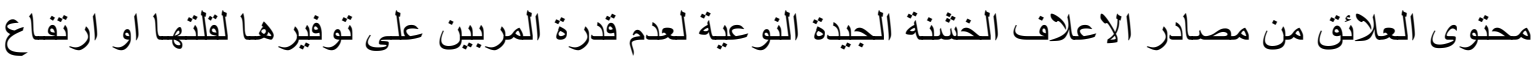

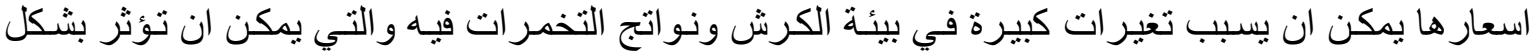

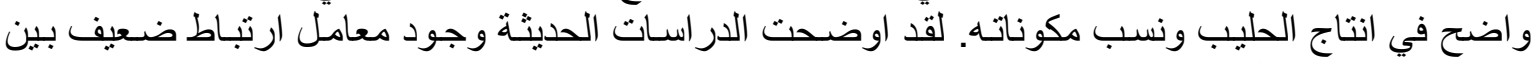

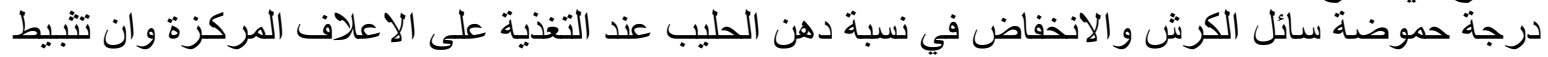

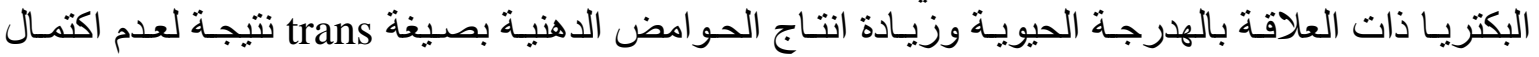

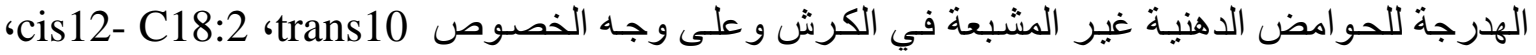

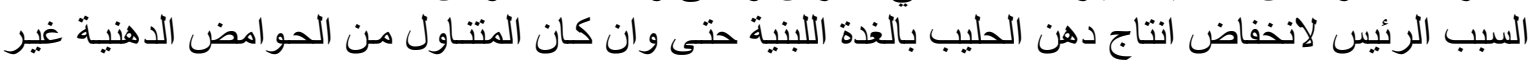

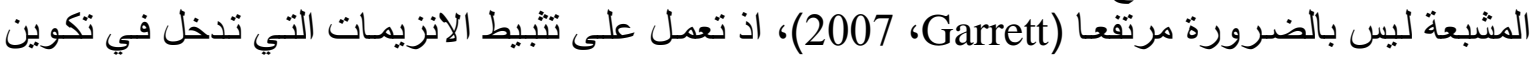

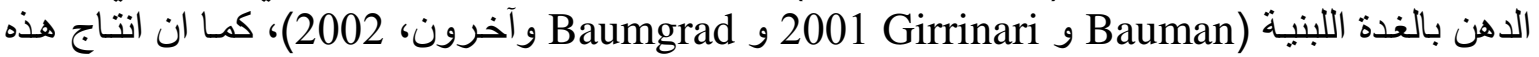

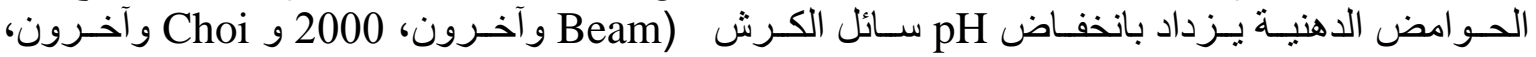

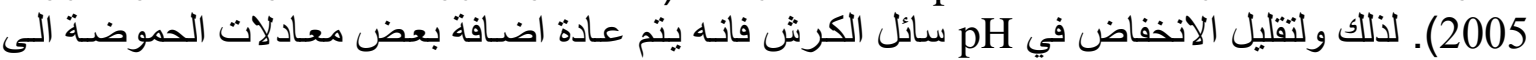
العلائق مثنل بيكاربونـات الصـوديوم (NaHCO

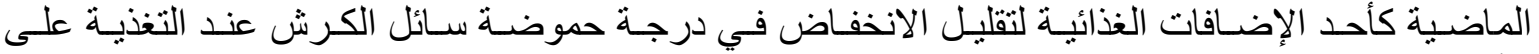

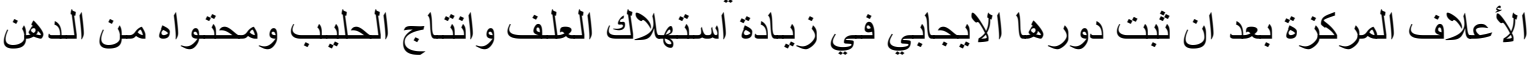




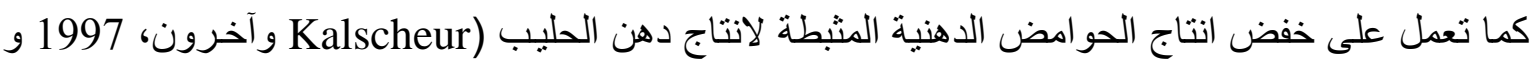
Kennelly وآخرون، 1999 و Apper-Bossard و آخرون،

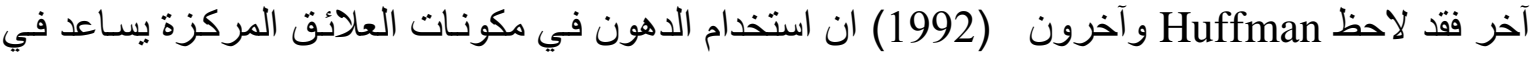

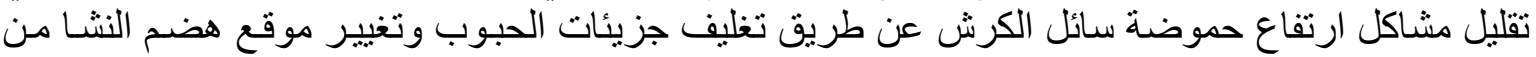

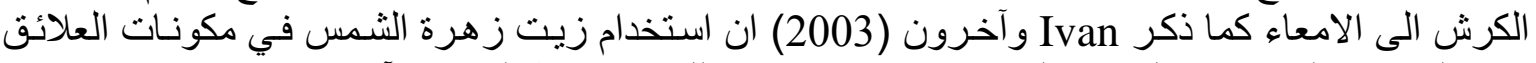

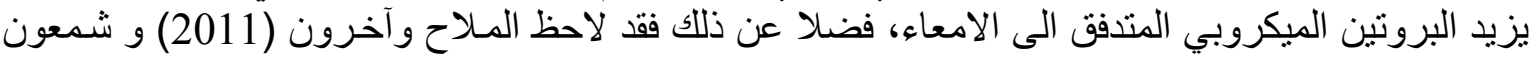

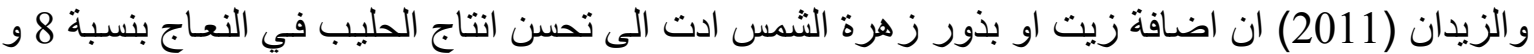

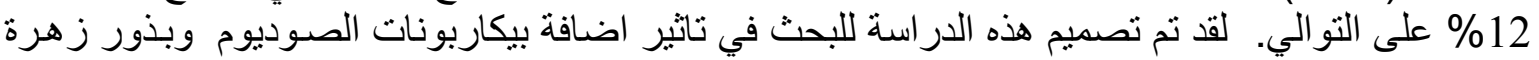
الثمس الى علائق النعاج في انتاج الحليب ونسب مكوناته في النعاج.

\section{مواد البحث وطر ائقه}

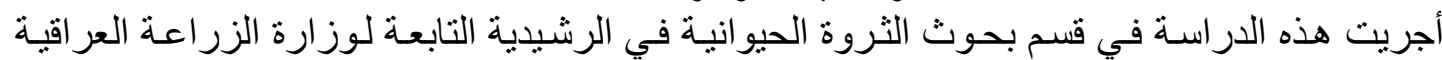

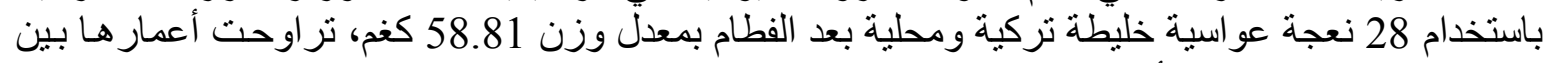

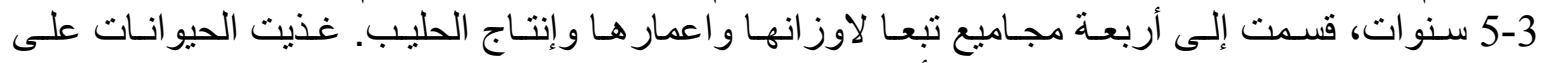

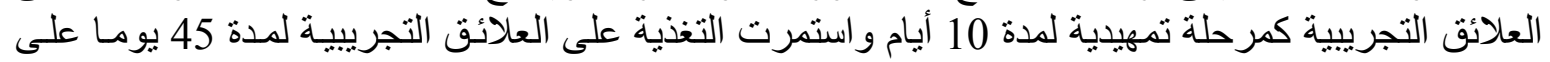

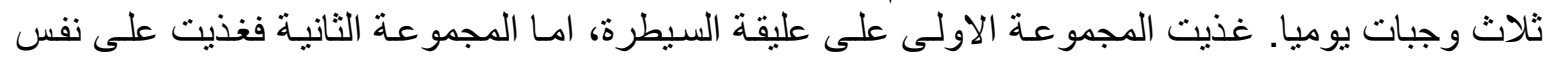

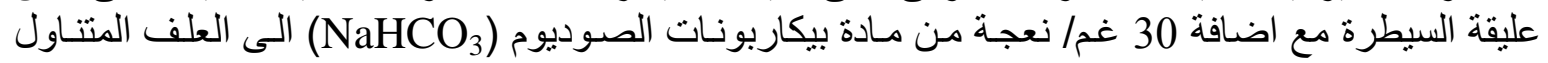

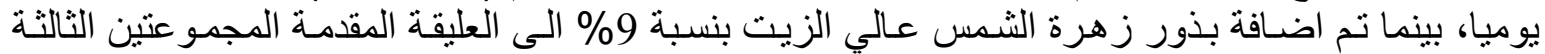

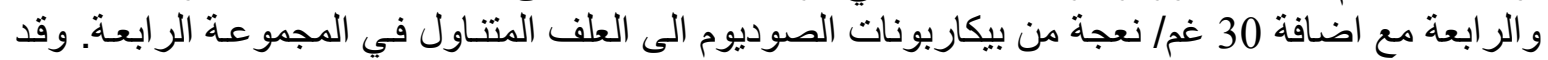

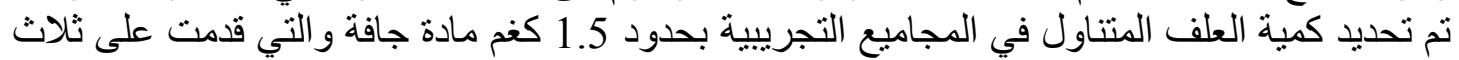

الجدول (1): المكونات و التركيب الكيميائي للعلائق التجريبية.

Table (1): Ingredients and chemical composition of experimental rations.

\begin{tabular}{|c|c|c|c|c|}
\hline \multicolumn{2}{|c|}{ بذور زهرة الشمس (SS) } & \multicolumn{2}{|c|}{ السيطرة (C) } & \multirow{2}{*}{$\begin{array}{c}\text { \% المكونات \% } \\
\text { Ingredients }\end{array}$} \\
\hline $\mathrm{NaHCO}_{3}+$ & $\mathrm{NaHCO}_{3-}^{-}$ & $\mathrm{NaHCO}_{3}+$ & $\mathrm{NaHCO}_{3}-$ & \\
\hline 44 & 44 & 53 & 53 & شعير (Barley) \\
\hline 31.5 & 31.5 & 31.25 & 31.25 & نخالة حنطة(Wheat bran) \\
\hline 9 & 9 & ---- & ---- & بذور زهرة الثمس (SS) \\
\hline 5 & 5 & 5 & 5 & كسبة فول صويا (SBM) \\
\hline 9 & 9 & 9 & 9 & تبن حنطة (wheat Straw) \\
\hline 0.5 & 0.5 & 0.75 & 0.75 & يوريا (Urea) \\
\hline 0.5 & 0.5 & 0.5 & 0.5 & ملح (Salt ) \\
\hline 0.5 & 0.5 & 0.5 & 0.5 & حجر كلس (Limestone) \\
\hline \multicolumn{5}{|c|}{ التحليل الكيميائي \% ( Chemical analysis \% ) } \\
\hline \multicolumn{2}{|c|}{94.27} & \multicolumn{2}{|c|}{93.39} & مادة الجافة (DM) * مافة \\
\hline \multicolumn{2}{|c|}{93.70} & \multicolumn{2}{|c|}{94.68} & مادة العضوية(OM) ( OM ) \\
\hline \multicolumn{2}{|c|}{7.15} & \multicolumn{2}{|c|}{4.01} & مستخلص الايثز (EE) ( \\
\hline \multicolumn{2}{|c|}{15.38} & \multicolumn{2}{|c|}{15.32} & البروتين الخام (CP) * ) \\
\hline \multicolumn{2}{|c|}{11.08} & \multicolumn{2}{|c|}{10.28} & الالياف الخام (CF) • \\
\hline \multicolumn{2}{|c|}{2.505} & \multicolumn{2}{|c|}{2.395} & الطاقـة الايضـية ميكـا سـعرة/ كغنم. Metabolic energy Mcal/ kg \\
\hline
\end{tabular}

$. \mathrm{C}=$ Control, $\mathrm{SS}=$ Sunflower seed, $\bullet$ Estimated according to Al-khawaja et al (1978)

(*Determined on dry matter base according to (Anonymous 2002)

وجبات يوميا. تم تسجيل انتاج النعاج من الحليب واخذ عينات من الحليب بنسبة 20\% كل خمسـة عثرة أيسام

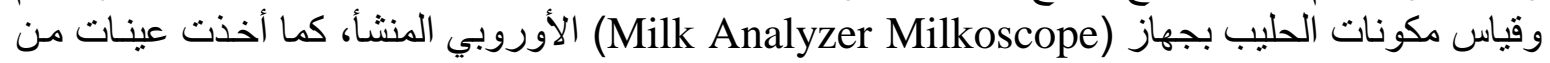
الدم من الوريد الوداجي بعد ساعتين من تقديم وجبـة العلف الصباحية وتم فصـل مصل الأوربـ الدم باستخدام جهاز 


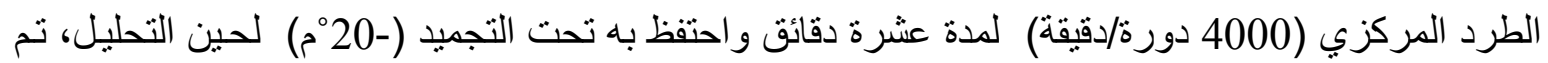

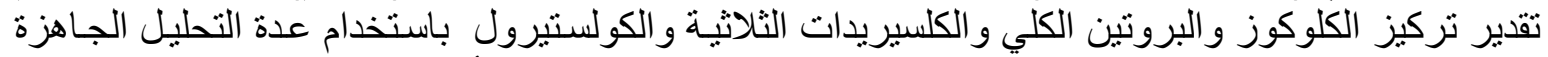
لفرنسية نوع (Biolabo) اما تركيز اليوريـا فقدر باستخدام عدة التحليل الألمانية (Biomerue) وباستخدام

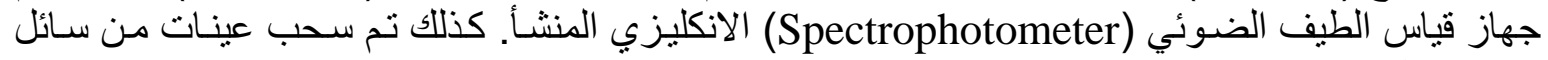

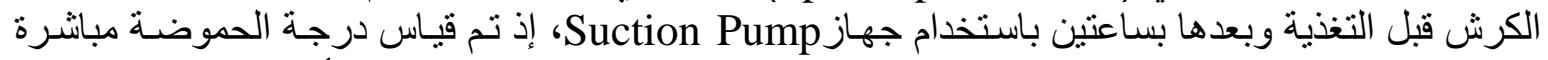

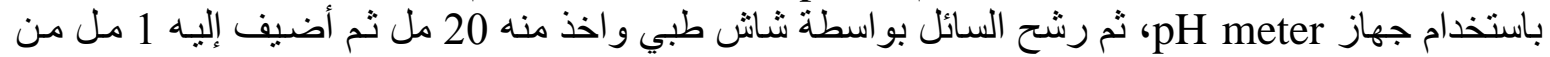

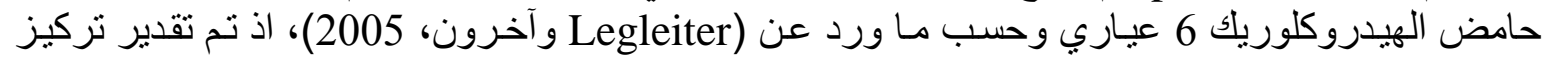

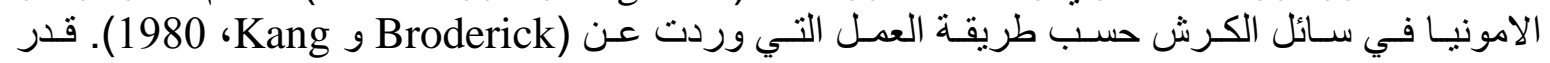

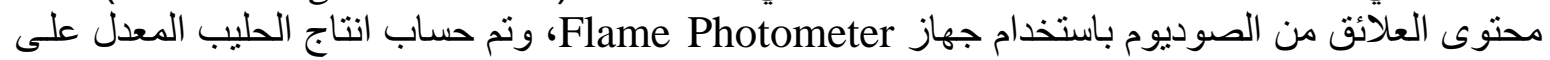

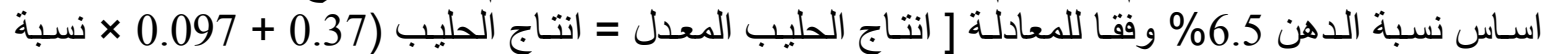
الدهن في الحليب) ] وحسب ما ورد عن (Pulina و آخرون، 2005)، . تم اجر اء التحليل الاحصـائي للبيانـات

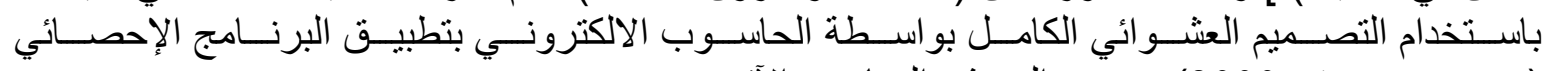

$Y i j=M+t i+\varepsilon i j$ (Anonymous) (2000) وحسب النموذج الرياضي الآتي:

(Yij(k ق قيمة المتوسط العام. iأثير العليقة i ti

(عij(k وتمت المقارنة بين المتوسطات باستخدام اختبار دنكن المتعدد الحدود (Duncan، لئنة 1955) لتحديد الفروقات المعنوية بين المتوسطات. بين المتيطات

\section{النتائج والمناقشة}

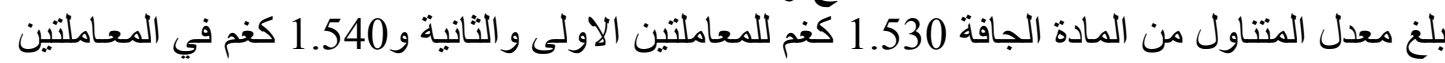

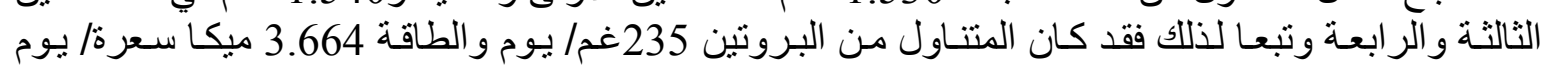

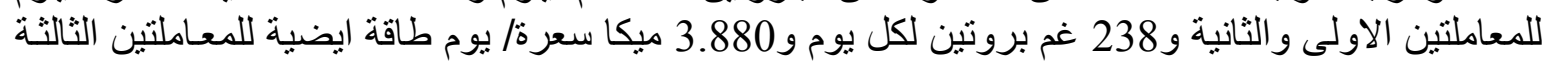

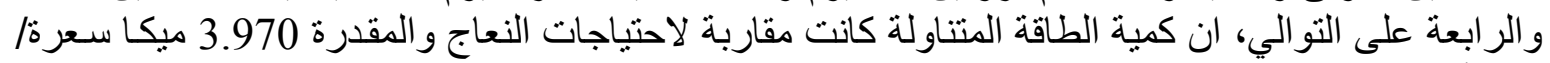

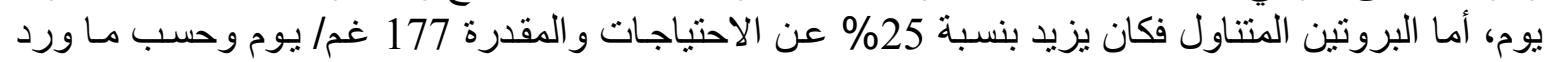

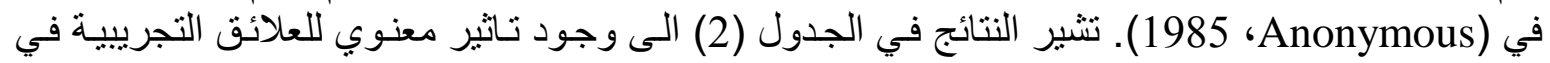

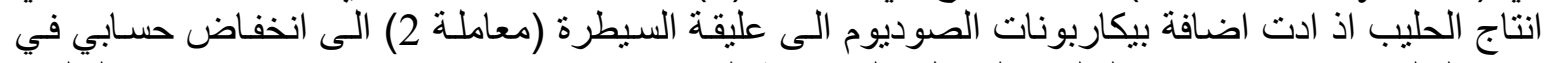
انتاج الحليب 727 غم/ يوم و الحليب المعدل على نسبة الدهن 6.5 \%

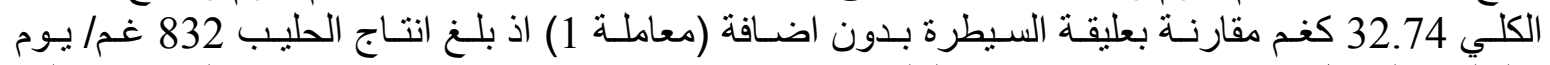

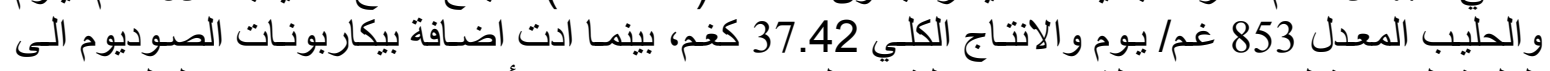

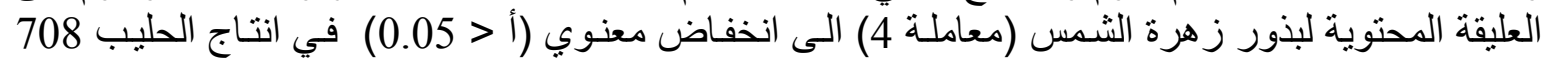

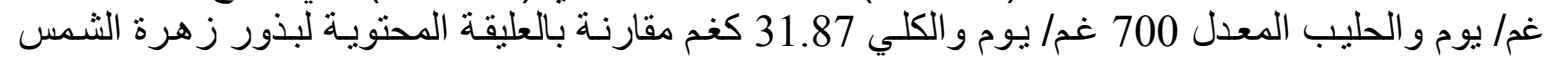

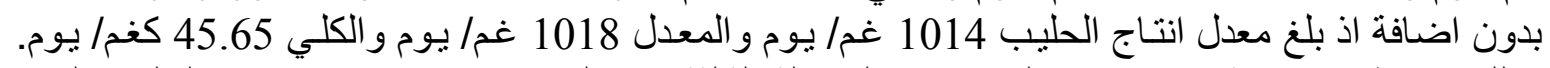

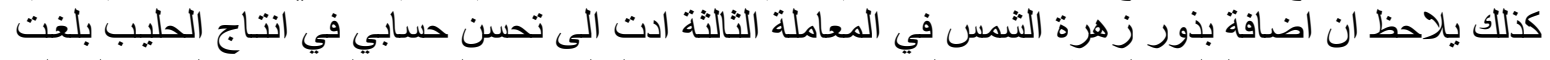

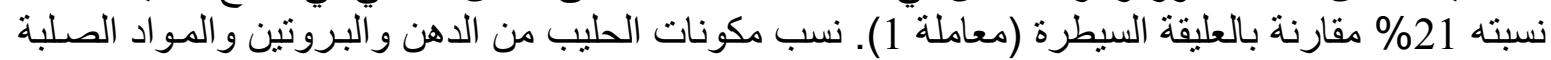

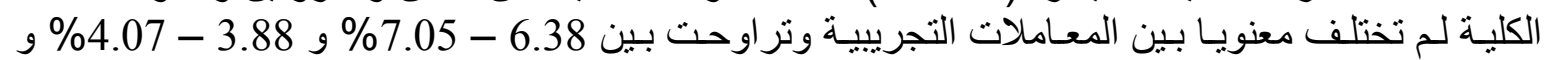

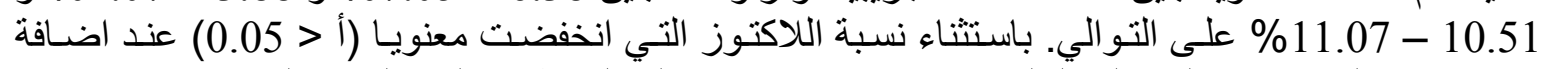

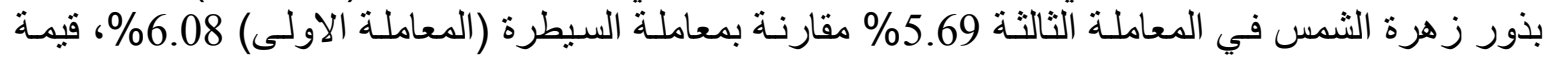

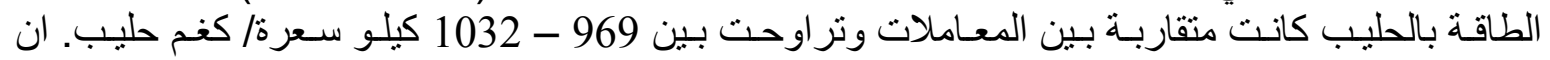

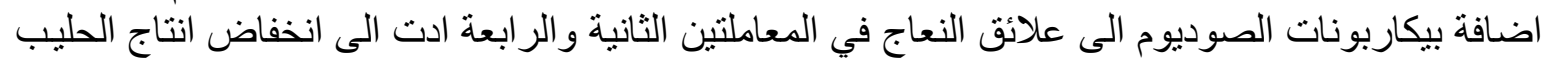

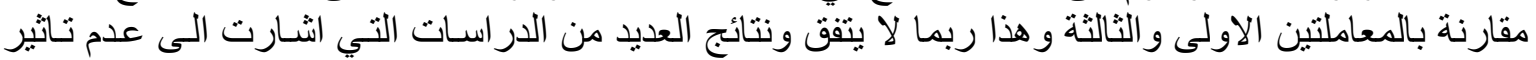

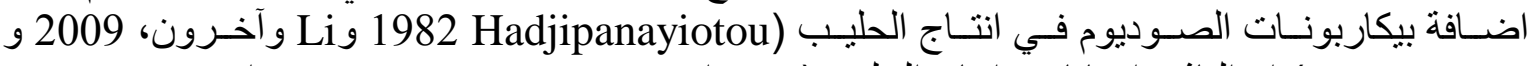
Caltiz

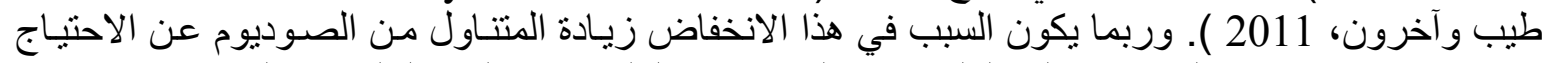
عند اضافة بيكاربونات الصوديوم الى العليقة، فقد بلغ محتوى العليقتين الاولى والثالثة من الصـوديوم 0.21 و 
Mesopotamia J. of Agric.

Vol. (41) No. (4) 2013
ISSN:2224-9796(Online)

ISSN: 1815-316x (Print)
مــــــلة زر اعــة الــر افـدين

المجلد (41) العدد (4) 2013

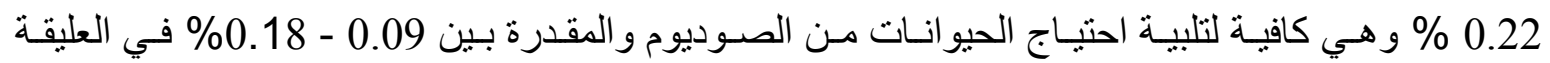
لم Anonymous)

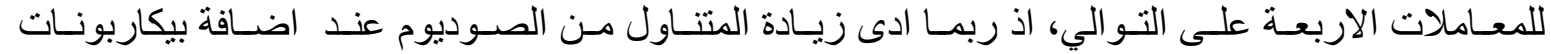

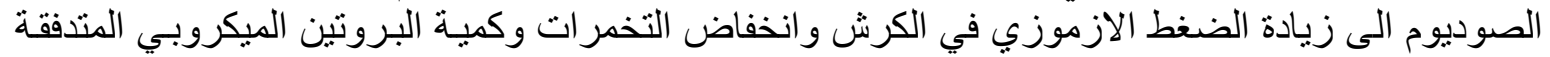

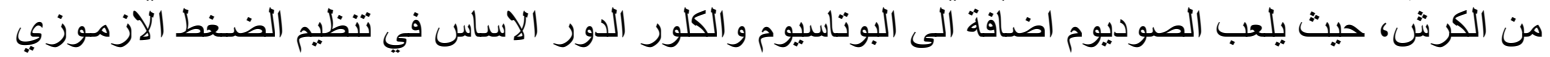

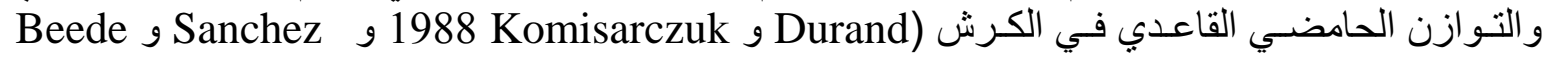

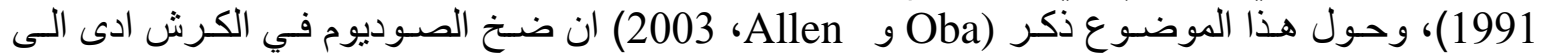

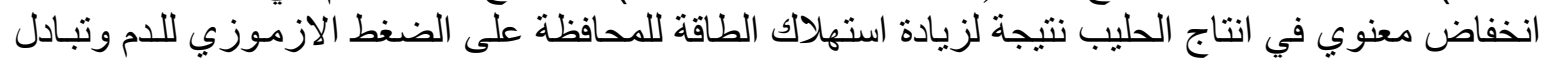

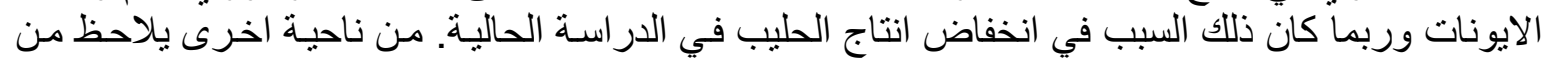

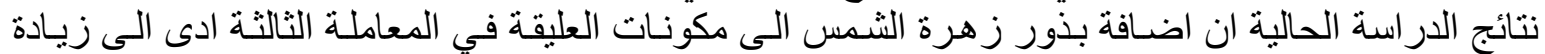

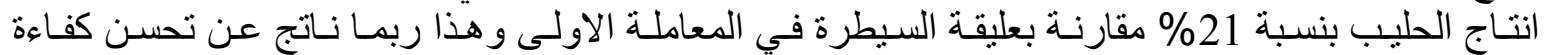

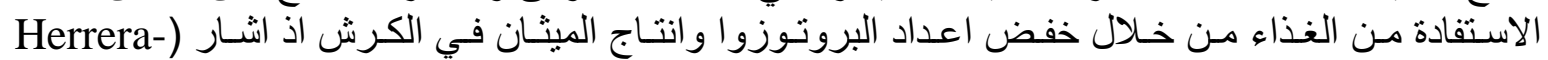

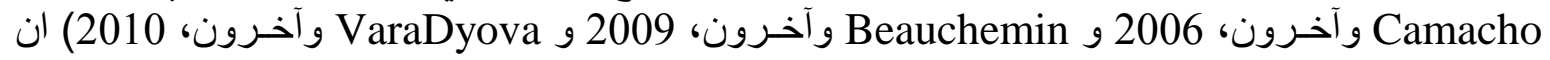

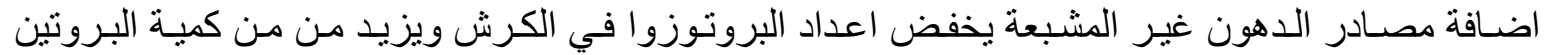

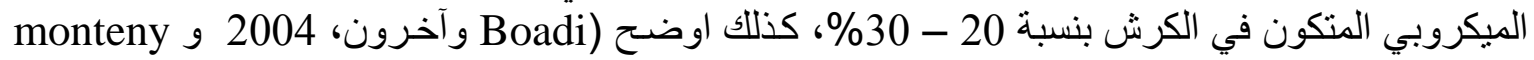

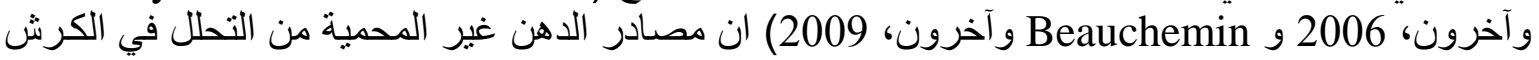

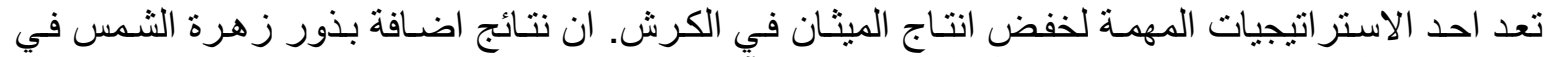

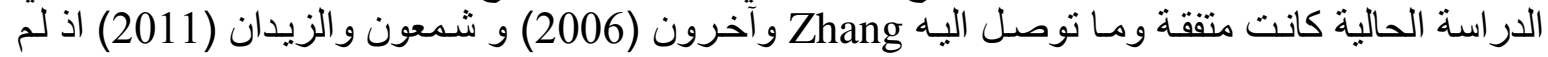
يشيروا الى وجود ناثير معنوي لاضافة بذور زهرة الثمس الى العلائق في انتاج الحليب ونسب مكوناته في

$$
\text { الجدول (2): تأثثر العلائق التجريبية في انتاج الحليب ونسبة مكوناته. }
$$

Table (2): Effect of experimental rations in milk yield and composition.

\begin{tabular}{|c|c|c|c|c|}
\hline \multicolumn{2}{|c|}{ بذور زهرة الثمس (SS ) } & \multicolumn{2}{|c|}{ السيطرة (C) } & \multirow{2}{*}{$\begin{array}{c}\text { الصفات } \\
\text { Parameters }\end{array}$} \\
\hline $\mathrm{NaHCO}_{3}+$ & $\mathrm{NaHCO}_{3}-$ & $\mathrm{NaHCO}_{3}+$ & $\mathrm{NaHCO}_{3}-$ & \\
\hline $70.23 \pm 708 b$ & a91.80 \pm 1014 & $92.28 \pm 727 b$ & $41.23 \pm 832 \mathrm{ab}$ & 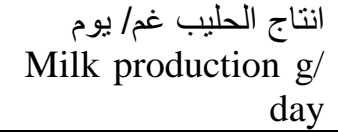 \\
\hline $100.5 \pm 700 \mathrm{~b}$ & a71.69 \pm 1018 & $122.7 \pm 766 a b$ & $53.49 \pm 853 \mathrm{ab}$ & $\begin{array}{rr}\text { انتاج الحليب المعدل غم/ } & \text { day } \\
\text { Corrected } & \text { g/ } \\
& \text { milk } \\
\end{array}$ \\
\hline $3.16 \pm 31.87 \mathrm{~b}$ & $\mathrm{a} 4.13 \pm 45.65$ & $4.15 \pm 32.74 b$ & $1.85 \pm 37.42 \mathrm{ab}$ & $\begin{array}{r}\text { انتاج الحليب الكلي. كغا كilk } \\
\text { Total } \\
\text { production. Kg }\end{array}$ \\
\hline $0.43 \pm 6.38$ & $0.30 \pm 6.54$ & $0.45 \pm 7.05$ & $0.33 \pm 6.76$ & نسبة الدهن\% 1 Fat percent \\
\hline $0.04 \pm 3.88$ & $0.05 \pm 3.91$ & $0.11 \pm 3.94$ & $0.05 \pm 4.07$ & $\begin{array}{r}\text { نسبة البروتين } \\
\text { Protein percent } \\
\end{array}$ \\
\hline $0.07 \pm 5.77 \mathrm{ab}$ & $0.11 \pm 5.69 b$ & $0.18 \pm 5.84 \mathrm{ab}$ & $0.08 \pm 6.08 \mathrm{a}$ & $\begin{array}{r}\text { نسبة اللاكتوز } \\
\text { Lactose percent }\end{array}$ \\
\hline $0.12 \pm 10.51$ & $0.11 \pm 10.61$ & $0.32 \pm 10.64$ & $0.15 \pm 11.07$ & نسبة المواد الصلبة الكلية \\
\hline $39.95 \pm 969$ & $26.17 \pm 985$ & $43.05 \pm 1032$ & $30.31 \pm 1011$ & 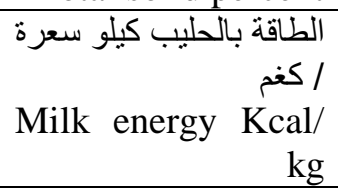 \\
\hline
\end{tabular}

تشير الحروف المختلفة افقيا الى فروقات معنوية (أ > 0.05).

النعاج باستثناء نسبة لاكتوز الحليب، كذلك لم تؤدي اضافة بذور زهرة الثمس الى فروقات معنويـة في انتاج الحليب في در اسات مشابهة اجريت على الابقار (Petit و آخرون، 2004 و Ngongoni و آخرون، 2009). 
الجدول (3): تأثير العلائق التجريبية في كمية مكونات الحليب.

Table (3): Effect of experimental rations in milk components yield.

\begin{tabular}{|c|c|c|c|c|}
\hline \multicolumn{2}{|c|}{ بذور زهرة الثمس (SS) } & \multicolumn{2}{|c|}{ السيطرة (C) } & \multirow{2}{*}{$\begin{array}{c}\text { الصفات } \\
\text { Parameters }\end{array}$} \\
\hline $\mathrm{NaHCO}_{3}+$ & $\mathrm{NaHCO}_{3-}^{-}$ & $\mathrm{NaHCO}_{3}+$ & $\mathrm{NaHCO}_{3}-$ & \\
\hline $7.74 \pm 45.17$ & $4.24 \pm 66.32$ & $9.25 \pm 51.25$ & $4.14 \pm 56.42$ & كمية الدهن غم/ يوم \\
\hline $2.89 \pm 27.47 \mathrm{~b}$ & $3.95 \pm 39.64 a$ & $4.09 \pm 28.65 b$ & $1.54 \pm 33.85 \mathrm{ab}$ & 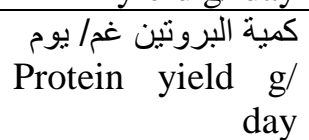 \\
\hline $4.33 \pm 40.85 b$ & $4.13 \pm 57.70 \mathrm{a}$ & $6.13 \pm 42.46 \mathrm{ab}$ & $2.31 \pm 50.58 \mathrm{ab}$ & 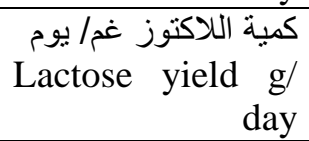 \\
\hline $112.10 \pm 686 b$ & $72.66 \pm 998 a$ & $120.75 \pm 750 \mathrm{ab}$ & $51.31 \pm 842 \mathrm{ab}$ & كمية الطاقة كيلو سعرة/ \\
\hline 11.49 & 18.28 & 12.07 & 14.04 & 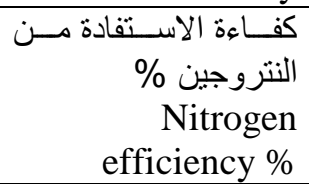 \\
\hline
\end{tabular}

Nitrogen Efficiency calculated according to Mikolayunas-Sandrock et al (2009). = $100 \times($ milk N $\mathrm{g} / \mathrm{d} \div \mathrm{N}$ intake $\mathrm{g} / \mathrm{d})$.

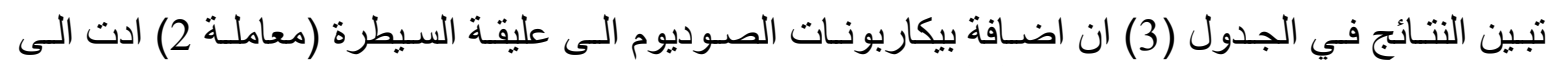

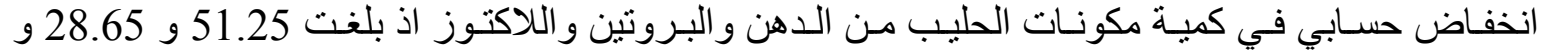

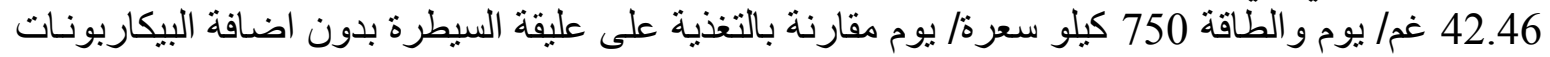

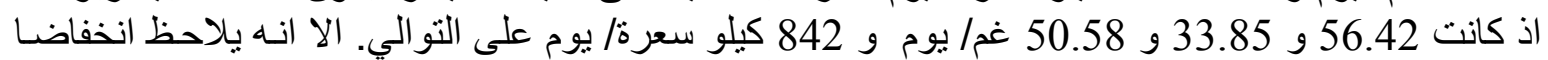

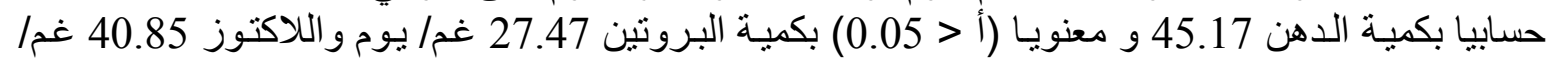
يوم والطاقة 686 كيلو سعرة/ يوم عند اضافة بيكاربونات الصوديوم اليكمة الى العليقة المحتوية لبذور زهرة

الجدول (4): تأثير العلائق التجريبية في درجة الحموضة وتركيز الامونيا في سائل الكرش.

Table (4): Effect of experimental rations in rumen $\mathrm{pH}$ and ammonia concentration.

\begin{tabular}{|c|c|c|c|c|}
\hline \multicolumn{2}{|c|}{ بذور زهرة الشمس (SS ) } & \multicolumn{2}{|c|}{ السيطرة (C) } & \multirow{2}{*}{$\begin{array}{c}\text { الصفات } \\
\text { Parameters }\end{array}$} \\
\hline $\mathrm{NaHCO}_{3}+$ & $\mathrm{NaHCO}_{3-}^{-}$ & $\mathrm{NaHCO}_{3}+$ & $\mathrm{NaHCO}_{3}-$ & \\
\hline $0.01 \pm 6.99$ & $0.16 \pm 6.87$ & $0.16 \pm 6.81$ & $0.08 \pm 6.76$ & درجة الحموضة قبل التغذية \\
\hline $0.13 \pm 6.11$ & $0.01 \pm 6.12$ & $0.08 \pm 6.07$ & $0.07 \pm 5.95$ & 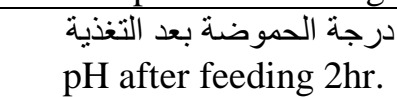 \\
\hline $0.42 \pm 5.86$ & $0.52 \pm 6.35$ & $0.26 \pm 6.31$ & $0.46 \pm 6.85$ & 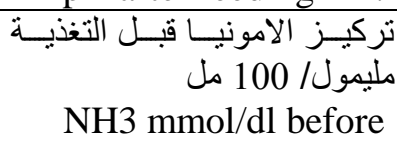 \\
\hline $0.83 \pm 6.67 b$ & $0.66 \pm 7.40 \mathrm{ab}$ & $0.05 \pm 8.76 \mathrm{a}$ & $0.44 \pm 7.40 \mathrm{ab}$ & 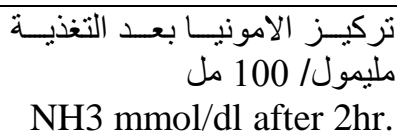 \\
\hline
\end{tabular}

تثير الحروف المختلفة افقيا الى فروقات معنوية (أ > 0.05).

الثمس (معاملة 4) مقارنة بالتغذية على نفس العليقة بدون اضـافة (معاملة 3) 64 اذ كانت كمية الدهن 69.32

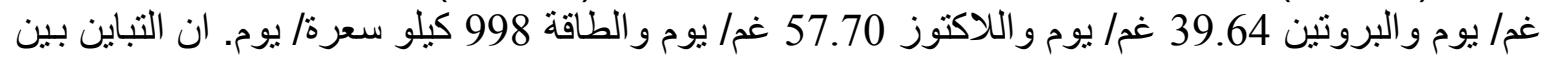

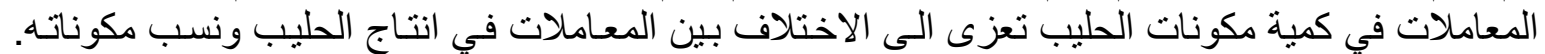

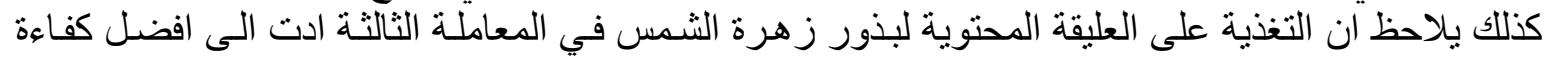


Mesopotamia J. of Agric.

Vol. (41) No. (4) 2013
ISSN:2224-9796(Online)

ISSN: 1815-316x (Print)
مـــــلة زر اعـــة الــر افـدين

المجلد (41) العدد (4) 2013

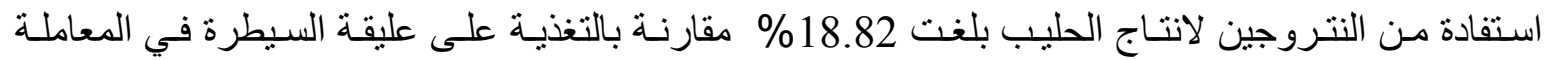

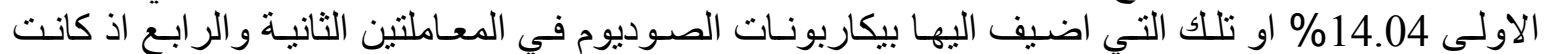

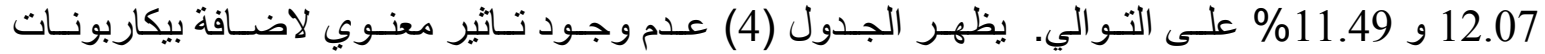

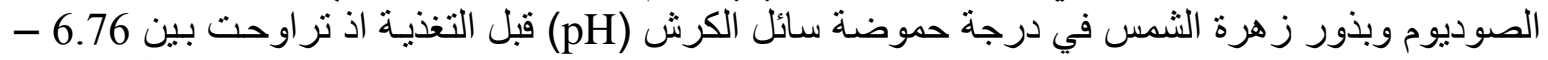

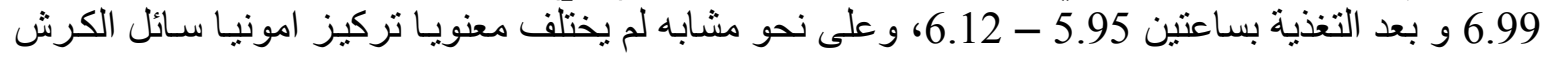

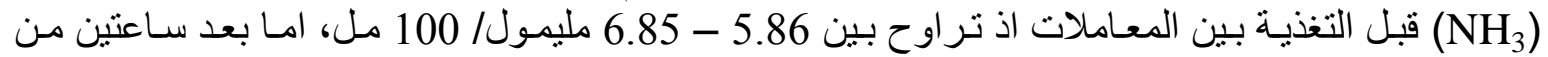

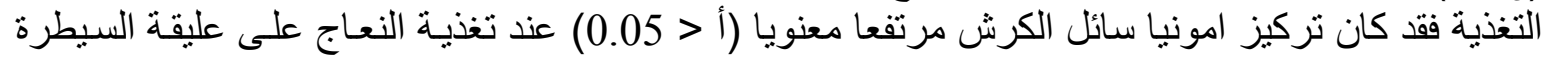

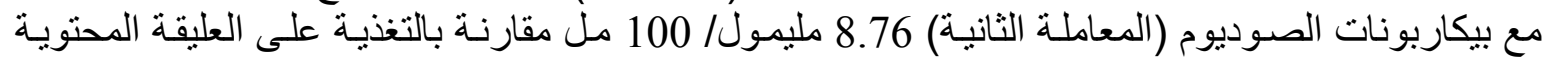

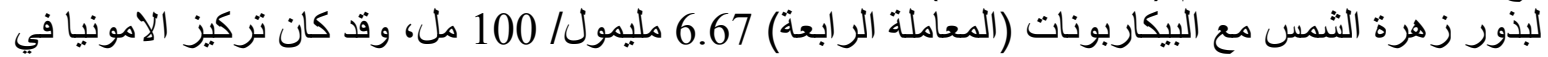

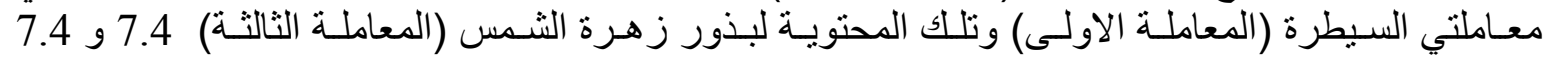

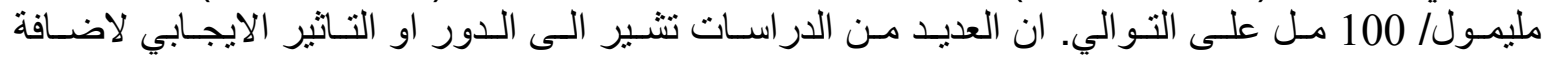
بيكاربونات الصوديوم في رفع pH سـائل الكرش (Paton)،

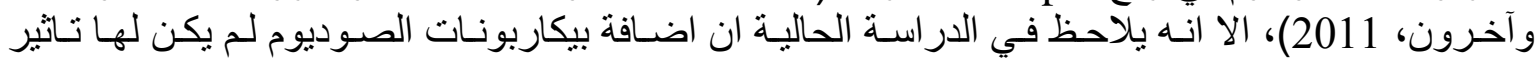

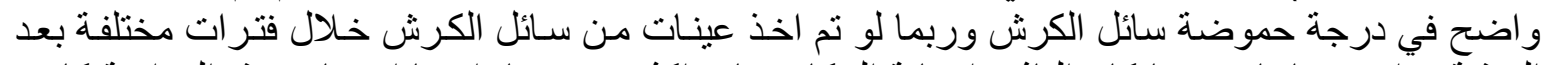

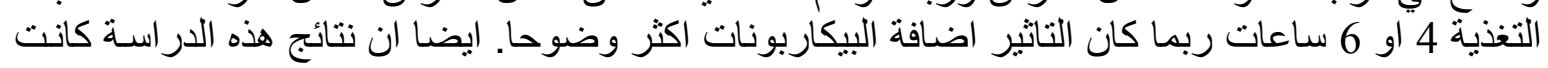

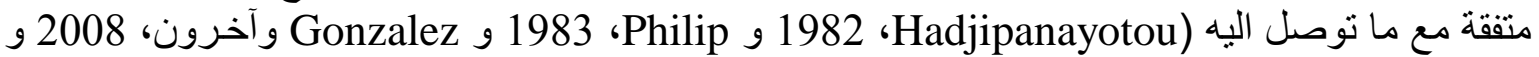

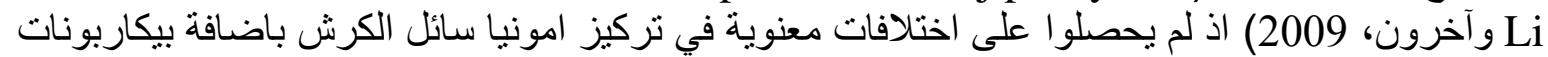

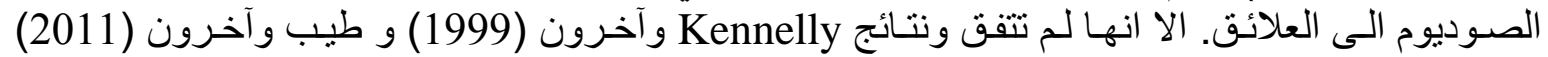

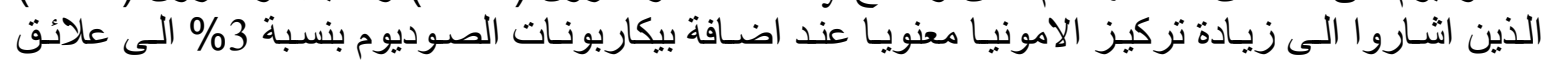

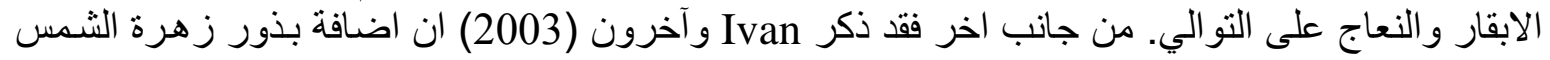

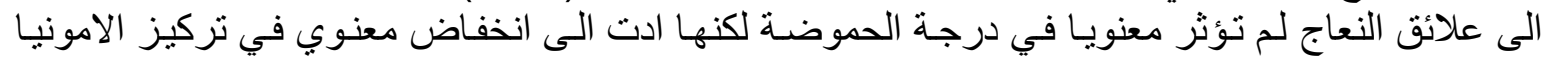
و هذا يتفق مع النتائج الدر اسة الحالية، بينما لم تتفق ونتائج Beauchemin و آخرون (2009) الذين اشناروا

الجدول (5): تأثير العلائق التجريبية في بعض قياسات الدم.

Table (5): Effect of experimental rations in some blood metabolites.

\begin{tabular}{|c|c|c|c|c|}
\hline \multicolumn{2}{|c|}{ بذور زهرة الثمس (SS ) } & \multicolumn{2}{|c|}{ السيطرة (C) } & \multirow{2}{*}{$\begin{array}{c}\text { الصفات } \\
\text { Parameters }\end{array}$} \\
\hline $\mathrm{NaHCO}_{3}+$ & $\mathrm{NaHCO}_{3-}^{-}$ & $\mathrm{NaHCO}_{3}+$ & $\mathrm{NaHCO}_{3}-$ & \\
\hline $3.66 \pm 58.35$ & $5.04 \pm 60.35$ & $7.18 \pm 54.95$ & $9.03 \pm 68.93$ & ملكلوكوز ملغم/ 100 \\
\hline $7.14 \pm 28.48$ & $3.69 \pm 29.13$ & $3.07 \pm 33.04$ & $6.15 \pm 36.08$ & 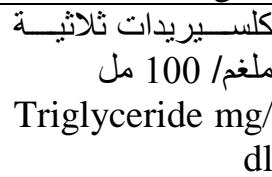 \\
\hline $\mathrm{a} 0.31 \pm 7.61$ & ab0.61 \pm 7.25 & $a b 0.27 \pm 6.82$ & b0.09 \pm 6.27 & 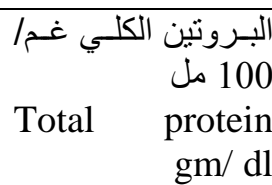 \\
\hline$a b 8.86 \pm 106.60$ & a18.40 \pm 120.65 & b10.21 \pm 72.05 & b12.64 \pm 73.60 & الكولسـتيرول ملغــ/ 100 مل \\
\hline$a b 4.07 \pm 61.36$ & $\mathrm{~b} 2.65 \pm 55.10$ & $a b 10.20 \pm 65.06$ & $\mathrm{a} 4.72 \pm 77.85$ & مليوريــا ملغــ/ 100 Urea mg/dl \\
\hline
\end{tabular}

تثير الحروف المختلفة افقبا الى فروقات معنوية (أ > 0.05).

الى حصول زيادة معنوية بتركيز الامونيا في سائل الكرش عند تغذية ابقار الحليب على عليقة تحتوي بذور

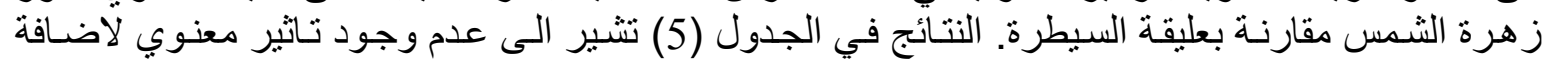

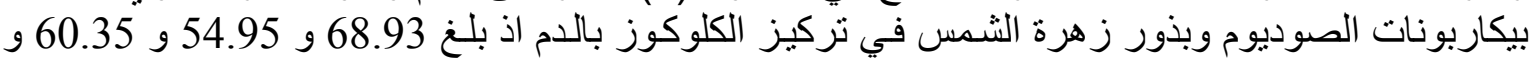




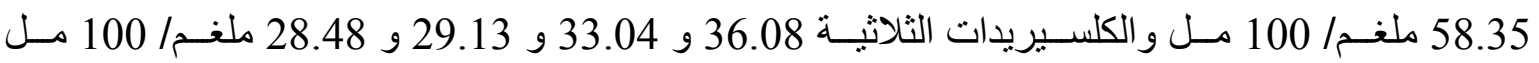

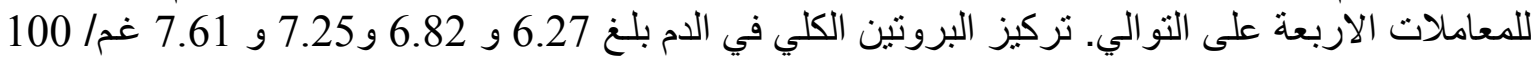

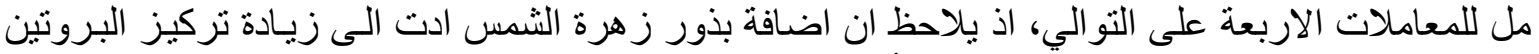
الكلي في الدم وقد كانت هذه الزيادة معنويـة (أ>

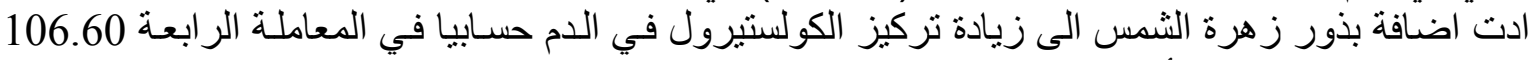

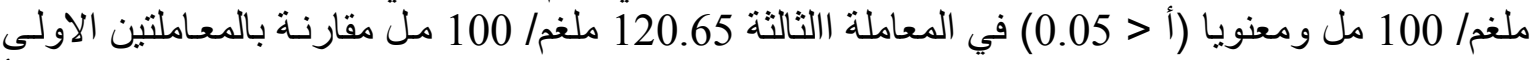

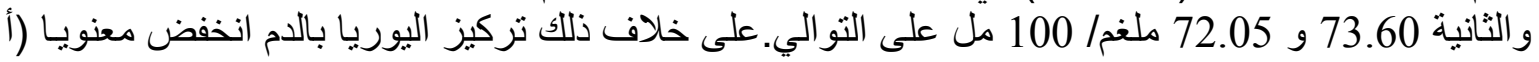

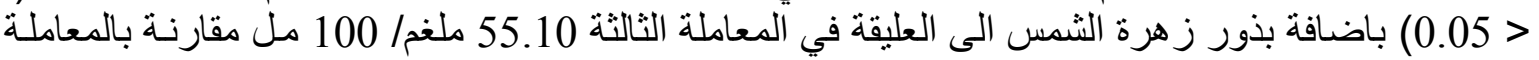

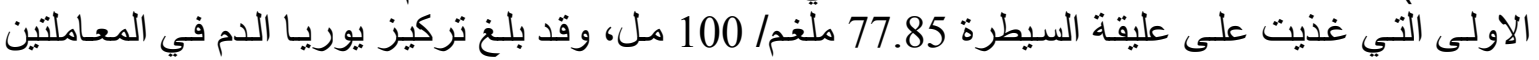

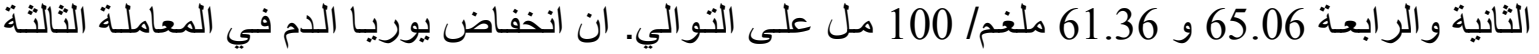

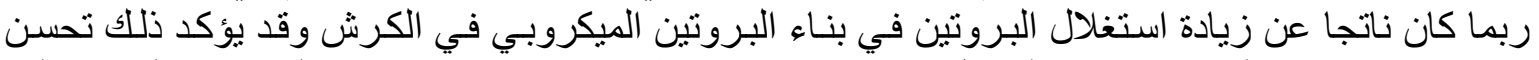

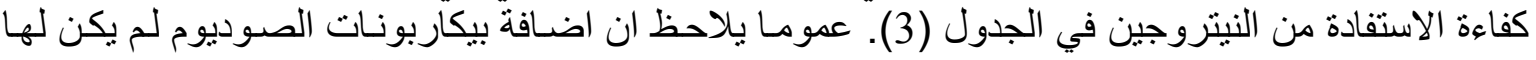

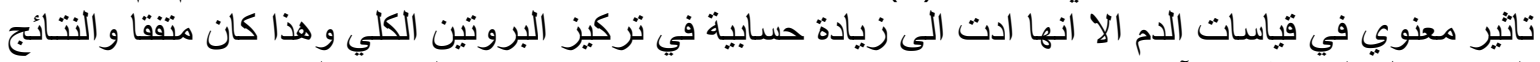

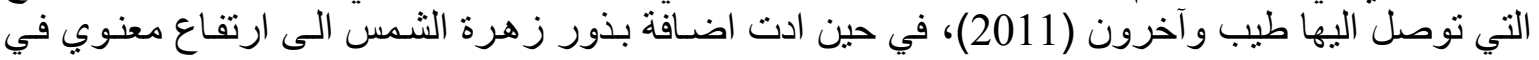

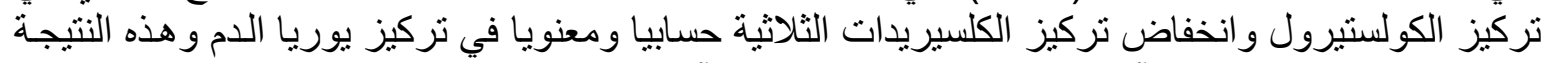

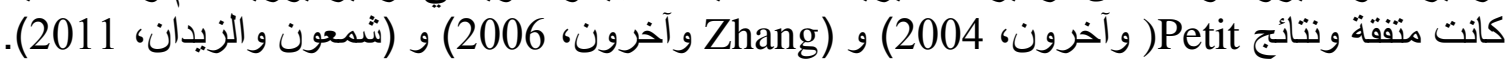

\title{
ADDING SUNFLOWER SEEDS AND SODIUM BICARBONATE TO THE RATIONS AND ITS EFFECT IN MILK PRODUCTION , COMPOSITION AND SOME BLOOD METABOLITES IN EWES
}

\section{$\begin{array}{lll}\text { O. D. ALMALLAH } & 1 & \text { M. N.ABDULLAH } \\ & \text { N. Y.ABO } & \text { N. G. HUSSAIN }\end{array}$}

${ }^{1}$ Anim. Res. Dept / College of Agriculture \& Forestry / Mosul Univ., Iraq ${ }^{2}$ Res. Dept. of Anim. Res. / State Board of Agric. Res. / Ministry of Agric.

E-mail: omaralmallah@yahoo.com

\begin{abstract}
This study was conducted in Al-Rashidiya animal breeding station, using 28 Awassi ewes (3-5 years old) with average body weight of 58.81. The ewes were paired randomly after weaning into 4 groups, the first fed on control ration which consist mainly of barley, soybean meal, wheat bran and wheat straw $\left(\mathrm{T}_{1}\right)$. The second group fed on control ration supplemented with $30 \mathrm{~g} /$ ewe of sodium bicarbonate $\left(T_{2}\right)$, while third $\left(T_{3}\right)$ and fourth $\left(T_{4}\right)$ groups fed on rations contain $9 \%$ sunflower seed with supplement $30 \mathrm{~g} /$ ewe of sodium bicarbonate to the intake of fourth group. Feed intake in all treatments restricted by $1.5 \mathrm{~kg}$ dry matter/ ewe. Results showed that feeding ewes with sodium bicarbonate supplement in $\mathrm{T}_{2}$ and $\mathrm{T}_{4}$ led to decreased daily and total milk production, significantly $(\mathrm{p}<0.05)$ in $\mathrm{T}_{4}$ which were $705 \mathrm{~g} /$ day and $31.87 \mathrm{~kg}$ compared with $\mathrm{T}_{3} 1014 \mathrm{~g} /$ day and $45.65 \mathrm{~kg}$ respectively. Milk component percentages unaffected significantly by treatments with exception milk lactose which was significantly $(\mathrm{p}<0.05)$ decreased in $\mathrm{T}_{3}$ $5.69 \%$ as compared with $\mathrm{T}_{1} 6.08 \%$. Results of blood metabolites was indicated that cholesterol concentration $120.65 \mathrm{mg} / \mathrm{dl}$, increased and urea concentration 55.10 $\mathrm{mg} / \mathrm{dl}$ decreased $(\mathrm{p}<0.05)$ in $\mathrm{T}_{3}$ compared with $\mathrm{T}_{1}$ which were 73.60 and $77.85 \mathrm{mg} /$ dl respectively. Results of rumen liquor was indicated significant $(p<0.05)$ decreased in ammonia concentration after $2 \mathrm{hr}$ of feeding in $\mathrm{T}_{4} 6.67 \mathrm{mmol} / \mathrm{dl}$ as compared with $\mathrm{T}_{2} 8.78 \mathrm{mmol} / \mathrm{dl}$.

Key words: sunflower seed, sodium bicarbonate, milk yield, ewes.
\end{abstract}




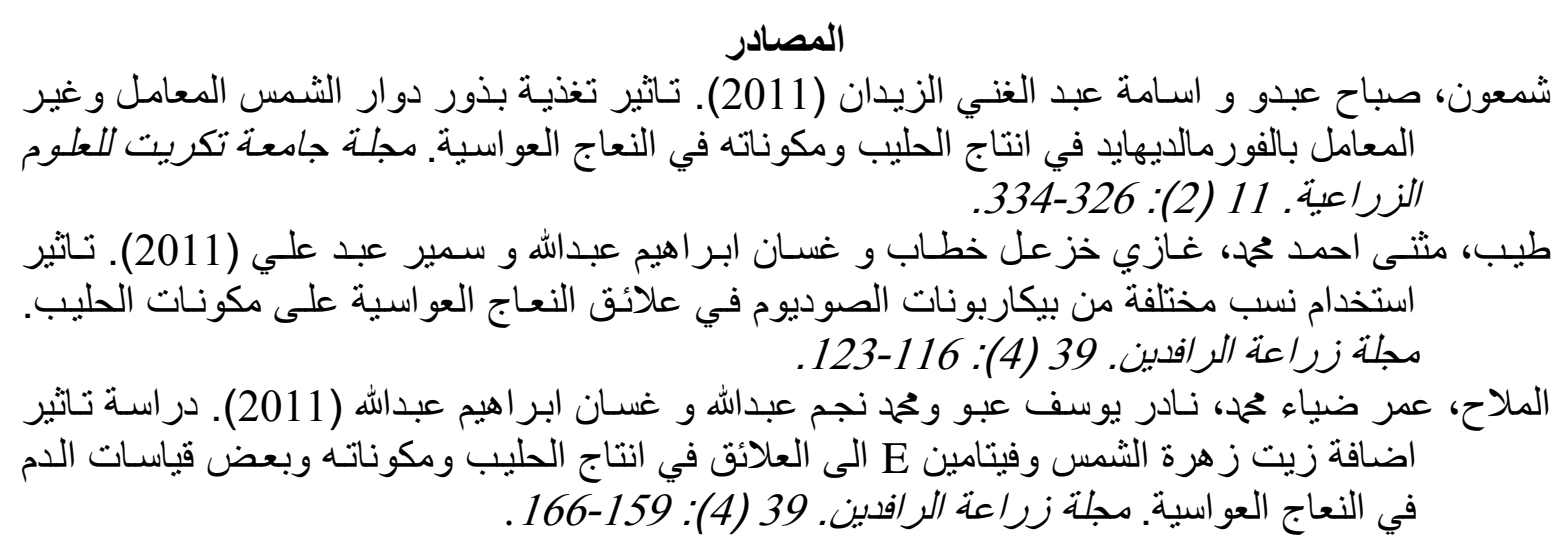

Al-Khawaja, A. K., S. A. Matti, R. F. Asadi, K. M. Mokhtar and S. H. Aboona (1978). The Composition and Nutritive Value Of Iraqi Feed Stuff, Division Publication, Ministry of Agricultre, Iraq.

Anonymous, (1985). The Nutrient Requirement Of Sheep, Sixth Revised Edition. National Academy press. Washington. DC.

Anonymous, (2000). Statistical analysis system. SAS institute, Inc. Cary. N. C.

Anonymous, (2002). Official Method of Analysis. $17^{\text {th }}$ Ed.(Association of Official Analytic Chemists), Washington, DC.

Apper-Bossard, E. ; J. L. Peyraud ; P. Faverdin and F. Meschy (2006). Changing dietary cation-anion differences for dairy cow fed with tow contrasting levels of concentrate in diets. Journal of Dairy Science, 89: 749-760.

Bauman, D. E. and J. M. Griinari (2001). Regulation and nutritional manipulation of milk fat: low-fat milk syndrome. Livestock Production science. 70: 15-30. Baumgrad, L. H.; E. Matitashvili ; B. A. Coral ; D. A. Dwyer and D. A. Bauman (2002). Trans 10, cis 12 conjugated linoleic acid depresses lipogenic rates and expression of genes involved in milk lipid synthesis in dairy cow. Journal of Dairy Science, 85: 2155-2163.

Beam, T. A.; T. C. Jenkins; P. J. Moate; R. A. Khon and D. L. Palmequist (2000). Effect of amount and source of fat on the rates of lipolysis and biohydrogenation of fatty acids in ruminal contents. Journal of Dairy Science, 83: 2564-2573.

Beauchemin, K. A.; S. M. McGinn; C. Benchaar and L. Holtshausen (2009). Crushed sunflower, flax, or canola seeds in lactating dairy cow diets: Effect on methane production, rumen fermentation, and milk production. Journal of dairy science, 92: 2008-1903.

Boadi, D.; C. Benchaar; J. Chiquette and D. Masse (2004). Mitigation strategies to reduce enteric methane emission from dairy cows: Update review. Canadian Journal Animal Science, 84: 319-335.

Broderick, G. A. and J. H. Kang (1980). Automated simultaneous determination of ammonia and total amino acids in ruminal fluid and in vitro media. Journal of Dairy Science, 63: 64-75.

Caltz, T. (2009). The Effect Of Acid Buff and Combination Of Acid Buff and Sodium Bicarbonate In Dairy Cow Diets On Production Response and Rumen Parameters. Department of Animal science. Stellenbosch University. MSC. Thesis.

Choi, Nag-Jin; Jee Young Imm; Sejong Oh; Byoung-ChulKim; Han-Joon Hwang and Young Jun Kim (2005). Effect of pH and oxygen on conjugated linoleic 
acid (CLA) production by mixed rumen bacteria from cow fed high concentrate and high forage diets. Animal Feed Science Technology, 123124: 643-653.

Duncan, C. B (1955). Multiple rang and Multiple "F" test. Biometric 11: 1-12.

Durand, M and S. Komisarczuk (1988). Influence of maigor mineral on rumen microbiota. Journal of nutrition, 118: 249-260.

Garrett, R. O. (2007). Sub acute ruminal acidosis in dairy herd: Physiology, Pathophysiology, Milk Fat Responses and Nutritional Management. American Association of Bovine Practitioners $40^{\text {th }}$ Annual Conference Vancouver, BC, Canada. 89-118.

Gonzalez, L. A.; A. Ferret; X. Manteca and S. Calsamiglia (2008). Increasing sodium bicarbonate level in high concentrate diets for heifers. I. Effects on intake, water consumption and ruminal fermentation. Animal, 2 (5): 705 712.

Hadjipanayiotou, M. (1982). Effect of sodium bicarbonate and of roughage on milk yield and milk composition of goats and of rumen fermentation of sheep. Journal of Dairy Science, 65(1): 59-64.

Herrera-Camacho, J.; J. A. Quintal-Franco; G. L. William ; R. Quijano-Cervera and J. C. Ku-Vera (2006). Dry matter intake, rumen fermentation and microbial protein supply in pelibeuey sheep fed low quality ration and different levels of corn oil. Interciencia Julio. 31 (7): 525-529.

Huffman, R. P.; R. A. Stock; M. H. Sindt and D. H. Shain (1992). Effect of fat type and forage level on performance of finishing cattle. Journal Animal Science. 70: 3889 .

Ivan, M.; T. Entz; P. S. Mir and T. A. McAllister (2003). Effect of sunflower seed supplementation and different dietary protein concentrations on the ciliate protozoa population dynamics in the rumen of sheep. Canadian Journal Animal Science, 83: 809-817.

Kalscheur, K. F.; B. B. Teter; L. S. Piperova and R. A. Erdman (1997). Effect of dietary forage concentrate and buffer addition on duodenal flow of transC18:1fatty acid and milk fat production in dairy cows. Journal of Dairy Science 80: 2104-2114.

Kennelly, J. J.; B. Robenson and G. R. Khorasani (1999). Influence of carbohydrate source and buffer on rumen fermentation characteristics, milk yield and milk composition in early-lactation Holstein cows. Journal of Dairy Science. 82: 2486-2496.

Legleiter, L. R.; A. M. Mueller and M. S. Kerley (2005). Level of supplemental protein dose not influence the ruminally undegradable protein value. Journal Animal Science 83: 863-870.

Li, X. Z. ; C. G. Yan ; R. J. Long ; G. L. Jin ; J. Shine Khuu ; B. J. Ji ; S. H. ChoiH. G. Lee and M. K. Song (2009). Conjugated linoleic acid in rumen fluid and milk fat and methane emission of lactating goats fed a soybean oil-based diet supplemented with sodium bicarbonate and monensin. Asian-Australian Journal of Animal Science, 22 (11): 1521-1530.

Mikolayunas - Sandrock, C., L. E. Armentano, D. L. Thomas and Y. M. Berger (2009). Effect of protein degradability on milk production of dairy ewes. Journal of Dairy Science. 92: 4507 - 4513. 
Monteny, G. J.; A. Bannink and D. Chadwick (2006). Greenhouse gas abatement strategies for animal husbandry. Agriculture Ecosystem Environment, 112: 163-170.

Ngongoni, N. T.; C. Mapiye; M. Mwale; B. Mupeta and M. Chimonyo (2009). Sunflower based rations for small-medium producing dairy cows. Pakistan Journal of Nutrition, 8 (4): 377-383.

Oba, M. and M. S Allen (2003). Effect of intraruminal infusion of sodium, potassium and ammonium on hypophagia from propionate in lactating dairy cows. Journal of dairy science, 86: 1398-1404.

Paton, L. J. (2005). Effect of sodium bicarbonate on reducing acidosis in cattle. Faculty of Gradient Studies (Animal Science). University of British Colombia. MSC. Thesis.

Petit, H. V.; C. Germiquet and D. Lebel (2004). Effect of feeding whole, unprocessed sunflower seeds and flaxseed on milk production, milk composition, and prostaglandin secretion in dairy cows. Journal of Dairy Science, 87: 3889-3898.

Philip, L. E. (1983). Effect of sodium bicarbonate on nitrogen utilization and feed intake by lambs. Canadian Journal Animal Science, 63: 613-621.

Pulina, Giuseppe; Nicolo Macciotta and Anna Nudda (2005). Milk composition and feeding in the Italian dairy sheep. Italian Journal of Animal Science. 4 (Suppl. 1): 5-14.

Sanchez, W. K. and D. K. Beede (1991). Interrelationship of dietary sodium, potassium and chlorine and cation-anion differences in lactation rations. $2^{\text {nd }}$ Florida Ruminant Nutrition Symposium. 31-41.

Varadyova, Z.; S. Kisidayova; A. Laukova and D. Jalc (2010). Influence of inoculated maize silage and sunflower oil on the in vitro fermentation ciliate population and fatty acid output in the rumen fluid collected from sheep. Czech Journal of Animal Science, 55 (3): 105-115.

Xu, S.; J. H. Harrison; R. E. Riley and K. A. Loney (1994). Effect of buffer addition to high grain total mixed rations on rumen $\mathrm{pH}$, feed intake, milk production, and composition. Journal of Dairy Science, 77: 782-788.

Zhang, R. H.; A. F. Mustafa and X. Zhao (2006). Blood metabolites and fatty acid composition of milk and cheese from ewes fed oilseeds. Canadian Journal Animal Science, 86: 547-556. 